3. direction and support for the development of an intervention in the setting or population.

This project involved liaison with NUI Galway to develop a workplace wellness specialism as part of this suite of programmes.

Results Following consultation with stakeholders, the module plan was drafted, submitted and approved. The platform 'Articulate Rise' was selected based on positive University experience and specialist materials developed. Recruitment and marketing resulted in 35 places offered and students are well advanced on the programme.

Discussion Evaluation of the programme is required and will be undertaken using University student feedback policies and processes.

\section{4d DEVELOPING HEALTHY WORKPLACES IN IRELAND - INTEGRATED APPROACH TO EMPLOYEE HEALTH, SAFETY AND WELLBEING}

Una Feeney. Eli Lilly Kinsale Limited, Dunderrow, Kinsale, Co. Cork

\subsection{6/oemed-2018-ICOHabstracts.610}

This introduces Eli Lilly's Live4Life wellbeing programme, which is a holistic integrated approach to employee Health, Safety and Wellbeing. It aims to link the organisation's safety culture journey with employee wellbeing - making it personal and empowering employees to 'Do the right thing' at work and at home. It outlines that in adopting a strategic approach to managing employee Health, Safety and Wellbeing; companies can make a dramatic impact - with relatively small effort and expenditure - by leveraging processes already in place in the organisation. It discusses the 'Work Positive' wellbeing survey and the development and spread of the Live4Life programme. It shows how management commitment and employee engagement has a positive effect within the organisation leading to increased education, participation and overall employee wellbeing.

\section{WORK AND SPIRITUALITY, NEW APPROACHES AND IDEAS - THE SPECIAL SESSION AIMS TO CLARIFY AND PROMOTE THE SPIRITUAL DIMENSION OF HEALTH AT WORK}

${ }^{1}$ Christophe Paris*, ${ }^{2}$ Frank van Dijk* ${ }^{1}$ Professor, University of Rennes, France; ${ }^{2}$ Professor emeritus, Coronel Institute of Occupational health, AMC, Amsterdam, The Netherlands

10.1136/oemed-2018-ICOHabstracts.611

M. Guillemin ${ }^{1}$, M. Zungu ${ }^{2}$, A. de Boer ${ }^{3}$, A. Mittal ${ }^{4}$, Y. Roquelaure $^{5}$, J. Rodriguez-Guzman ${ }^{6}$, R. Nicholas ${ }^{7}$

${ }^{1}$ Professor emeritus, University of Lausanne, Switzerland

${ }^{2}$ Dr. National Institute for Occupational Health, Pretoria, South Africa

${ }^{3}$ Dr. Coronel Institute of Occupational health, AMC, Amsterdam, The Netherlands

${ }^{4}$ Dr. OH and S Consultancy Services, New Delhi, India

${ }^{5}$ Professor, University of Angers, France

${ }^{6}$ Dr. Regional Advisor, Pan-American Health Organisation/ World Health Organisation, Washington, DC

${ }^{7} \mathrm{Mr}$. Robin Nicholas Communication, Santa Fe, USA 1645a THE SPIRITUAL DIMENSION IN OCCUPATIONAL HEALTH: A KEY EMERGING ISSUE

M Guillemin. University of Lausanne, Switzerland

10.1136/oemed-2018-ICOHabstracts.612

Occupational Health $(\mathrm{OH})$ is dedicated not only to prevent diseases but also to promote health in its global dimension, including the spiritual wellbeing. This dimension must not be confused with mental wellbeing or religious beliefs, since it refers to intangible assets and deep feelings such as ethics, compassion, dignity, tolerance, engagement, inclusiveness, sustainability and individual growth among others. In this respect, spirituality is complementary to the other dimensions of wellbeing at work such as the physical, mental and social ones.

Though this dimension has not been much studied in the field of Occupational Health up to now, it is more and more an emerging demand from people willing to give sense to their life by allowing these intangible assets to become factors of their wellbeing at work and in their private life. Surveys in Europe have shown that the young generation prefers a meaningful job than a lucrative one. The meaningfulness of work strongly depends on its coherence with the fundamental values of individuals. Moreover, it has been shown that the 'Sense of Coherence', the basic concept of Salutogenesis - science focusing on factors that support human health and well-being, rather than on factors that cause disease - is closely linked with 'good health' and implicitly related to spiritual values of individuals. Therefore, it becomes more and more obvious that $\mathrm{OH}$ has to open to this new field of research and to the transfer of these new factors into practice.

And the Science of Management too has opened its research on its spiritual dimension for many years now, as illustrated by the Spiritual Division of their international Academy of Management. New forms of management focusing on care (benevolent leadership for example) belong to these emerging issues that $\mathrm{OH}$ should promote and develop since they contribute to set up healthy and productive workplaces.

\section{5b UBUNTU THE AFRICAN SPIRITUALITY IN OCCUPATIONAL AND ENVIRONMENTAL HEALTH AND SAFETY}

M Zungu. National Institute for Occupational Health a division of the National Health Laboratory Services, Johannesburg, South Africa

10.1136/oemed-2018-ICOHabstracts.613

South Africa is an upper middle-income economy with a fledging tertiary sector (service, financial and knowledge economy) rooted in the primary sector (mining and agriculture) and secondary sector (manufacturing). South Africa's diverse economy has contributed immensely to the mortality and morbidity of the South African workforce as a result of occupational injuries and diseases. While there is limited data on occupational injuries and diseases for South Africa namely rock fall accidents and silicosis in mining; tuberculosis and musculoskeletal injuries in healthcare; motor vehicle accidents and fall from heights in construction; noise induced hearing loss as well as mental health issues across industries; these are but a few causes for concern in occupational and environmental health and safety (OEHS) in South Africa. 